\title{
Multidimensional Reading of Snow White in China
}

\author{
Haixia Yang \\ School of Foreign Languages, North China Electric Power University, Changping District, Beijing, China \\ Liqing Kang \\ School of Foreign Languages, North China Electric Power University, Changping District, Beijing, China
}

\begin{abstract}
To introduce Chinese scholars' reading of the American novel, Snow White, to the outside world, three representative analyses, among others - to which the theoretical vehicles of deconstruction, intertextuality and cognitive narratology are applied-are individually presented in detail. In the progress of their analyses they take the novel's ancient counterpart, the fairy tale (Snow White and the Seven Dwarfs), as object for deconstruction, benchmark and background respectively. The old story thus remains an indispensable source to decipher the multiple layers of meaning of the postmodern novel.
\end{abstract}

Index Terms -intertextuality, cognitive narrative, deconstructionism

\section{INTRODUCTION}

Snow White is a $19^{\text {th }}$-century German fairy tale well-known across the world. It was first published in 1812 by the Brothers Grimm. One and a half centuries later in 1965, American postmodernist experimental author Donald Barthelme published a novel entitled the same and gained popularity. Since then, his novel had been studied by generations of readers worldwide. At the turn of the $21^{\text {st }}$ century, Chinese readers started to interpret it from a couple of distinct perspectives. By employing different critical theories such as intertextuality, deconstructionism and cognitive poetics and the like, they had put plausible interpretations on the same text. This article intends to illustrate three of them individually.

\section{INTERTEXTUAL READING}

The first one, Intertextual Reading of Barthelme's Snow White by Li Yuping analyses the text on the basis of Theory of Intertextuality by Julia Kristeva, who maintained that "any text is constructed as a mosaic of quotations; any text is the absorption and transformation of another"(Kristeva, 1986, p. 37). Postmodern works are no exception.

$\mathrm{Li}$ starts her comment with a brief introduction to the theory. Then she writes: traditionally, the reality presented and the intention of the author are regarded as the two keys to understanding realistic novels rather than postmodernist texts; but the theory of intertextuality by Kristeva is to take their place; and by binding the text itself with its original version, the postmodernist novel would make sense. Fragments in the new text deconstructs the meaning of its prototype in the old tale, yet their reorganization helps decipher multiple shades of meaning which may exceed even the author's expectations.

As far as its target text is concerned, Li assumes that the novel Snow White is neither a complete nor self-sufficient closed system. Only through intertextual reading, combining the present text with the fairy tale in absence, could layers of meaning of the novel be figured out. Evidences are presented as follows:

In the tale Snow White lives with seven dwarves in the forest and is saved by a prince. In Barthelme's novel, however, Snow White is a 22-year-old, intermingling seven dwarves who made their living by washing buildings and making baby food in a Chinese factory. She herself works as a horsewife - derivation of housewife, which is a word coined by the author - cooking and washing for them and screws with them. Weary of the boring life, she is expecting a princely guy, Paul, who turns out to be a wizard despite of his royal blood. Unable to save Snow White, Paul escapes to monastery and finally dies of poisoned wine prepared for Snow White out of jealousy by Jane, who is presented as a witch to conspire to poison Snow White. After Paul's death, Snow White casts chrysanthemum on Paul's grave and revirginizes and rises to the sky.

By combined reading, the moral lessons given by the stereotyped fairy tale are challenged, the boundary between good and evil is blurred. Snow White is no longer the incarnation of kindness or innocence. She is now well educated at college, studied courses in English literature, art, psychology, personal resources, but is indulged in "venereal life" and writes dirty poems. Seven dwarves are not redemption of justice and courage any more as in the old story. They are, instead, "complex bourgeois who are at a loss", who worship "the almighty penny." One of them would "pay her a thousand dollars, all just to ease this wrinkle in the groin" (Barthelme, 1965, p. 64). And Paul, the former prince, is now and here merely a sordid coward. Having been project in the shape of Snow White's longing, boredom, ennui and pain, 
Paul is awaited by Snow White to save her. Unexpectedly, her ebony black hair "has made him terribly nervous". To avert his princely responsibility, Paul had at first hidden himself at a monastery in Nevada, then fled to France to work as a music guide, and finally to Rome in a postal service before approached Snow White just to spy on her naked body through an underground observatory he had built up on purpose. This way, his sexual desire was satisfied but did not need to shoulder princely responsibility.

In addition, the novel blurs the boundary between fact and fiction, assuring the reader that what is written in the text is reality, unlike the fairy tale in which there are clear borderline between virtual and real worlds: the very beginning "long long ago" brings the reader to an imaginary realm and the end - "they since then live a happy life"-returns to the physical reality.

In terms of implementing strategy of intertextuality, the author of the dissertation confirms that the novel retains some characteristics of fairy-tale figures. For instance, Snow White has still black ebony hair and snow white skin, the seven dwarves remain short and hard-working. Whereas the questionnaire between chapter I and chapter II is regarded as part of intertextuality strategy as it reminds the reader to tie the hypertext (the novel) up with the hypotext (the tale) (Genette, 1997, p. 5). Besides, words in upper case and larger size work as reminders of the fairy tale, one of the outstanding examples is as follows:

\section{THE PSYCHOLOGY OF SNOW WHITE IN THE AREA OF FEARS, SHE FEARS MIRRORS APPLES \\ POINSONED COMBS (Barthelme, 1965, p. 17)}

The scholar, Li, also maintains that the novel Snow White comprises incoherent fragments with thread of intertextuality running through them. Ronald Barthelme has said "Fragments are the only forms I trust." Intertextual strategy, meanwhile, enables fragments (news, letter, commercial, academic work abridged, conscious flow, absurd argument) to signify, and the reader could thus catch multiple layers of meaning. On the first page, the vertical line of spots of Snow White's freckles is supposed to underline its visual effect as a non-verbal text.

As for aesthetic effect the novel Snow White created, Roland Barthes' theory is quoted as saying; "Texts are divided into two types, text of pleasure and text of bliss" (Barthes, 1975, p. 14). The latter refers to "the text that imposes a state of loss, the text that discomforts perhaps to the point of a certain boredom, unsettles the readers' tastes, values, memories, brings to a crisis his relation with language" (Barthes, 1975, p. 14). The novel Snow White is taken as a text of bliss; whereas its corresponding fairy tale a text of pleasure, whose characters and plot create expectation in readers. The fragmentary novel Snow White is against the reader's expectation: its embodiment of courage and justice in fairy tale turns out to be the mediocre or even the despicable; its plot with the thread running through the story reduces to fragments without linear or causal connection. Still, with intertextual reading strategy in mind, the reader would, at long last, feel pleasure mixed with pain, called bliss.

The conclusion Li has drawn is that only with reading strategy of intertextuality could postmodern novels be fully understood, because "postmodernism features intertextuality. Nowadays, postmodernism and intertextuality are synonymous" (Bertens, 1997, p. 249).

This is a questionable conclusion: On the one hand, the text can be interpreted through the theory of intertextuality. But, on the other, it should not be limited to that. There is another way out. As Snow White by Barthelme is universally acknowledged as a postmodern piece, it could be explained by deconstructionism. For example, Ihab Hassan concludes in his The Postmodern Turn: Essays in Postmodern Theory and Culture that 5 out of the 11 characteristics of postmodernist work are deconstructive.

\section{DECONSTRUCTIONIST INTERPRETATION}

The second essay "Snow White and the Postmodern Deconstruction by Ma Hanguang puts deconstructionist vehicle into play. In that essay he argues that Barthelme deconstructed Grimm Brothers' tales by parodying. Modern city dwellers replace fairy figures who live in the forest; the objective yet abstract characters substitute fictitious images, thus their mythical and transcendental color fades away. That the flattened characters without vivid character-the seven dwarves and the prince - take the place of heroes in the tale is overshadowed by their original counterparts. Irony and parody unsettle solemnity, seriousness, and sobriety of the poignant fairy tale, which is reduced to a ridiculous joke. Collage consisting of meaningless and fragmented discourse indicates helplessness of modern life.

In the first place, narration of the story is repeatedly interrupted by divergent discourses. Those that are closely related to its original story require frequent comparison or contrast between the novel and the tale, creating the effect of irony or mimicry, for instance:

PAUL HAS NEVER BEFORE REALLY SEEN SNOW WHITE AS A WOMAN (Barthelme, 1965, p. 150)

Heterogeneous fragments without coherence bring a verbal collage into being, while capitalized bold letters of the first words of every single fragment make great play of the effect of the collage. Those that are irrelevant to the tale indicate the meaninglessness and/or oddity of language itself.

SNOW WHITE THINKS: THE HOUSE ... WALLS ... WHEN HE DOESN'T... I'M NOT... IN THE DARK ... SHOULDERS ... AFRAID ... THE WATER WAS COLD ... WHAT TO KNOW ... EFFORTLESSLY ... (Barthelme, 
1965, p. 165)

The following seemingly pedantic discourse offers no information insightful. But assortment of such materials convinces the reader that language has degraded to incomplete, semantically wrong fragments. And parody of all different genres further assure the reader that the tradition of language and literature has been shaky.

THE VALUE THE MIND SETS ON EROTIC NEEDS INSTANTLY SINKS AS SOON AS SATISFACTION BECOMES READILY AVAILABLE. SOME OBSTACLE IS NECESSARY TO SWELL THE TIDE OF THE LIBIDO TO ITS HEIGHT, AND AT ALL PERIODS OF HISTORY, WHENEVER NATURAL BARRIERS HAVE NOT SUFFICED, MEN HAVE ERECTED CONVENTIONAL ONES (Barthelme, 1965, p. 76).

IT WAS NOT UNTIL THE $19^{\mathrm{TH}}$ CENTURY THAT RUSSIA PRODUCED A LITERATURE WORTHY OF BECOMING PART OF THE WORLD'S CULTURAL HERITAGE. PUSHKIN DISPLAYED VERBAL FACILITY. GOGOL WAS A REFORMER. AS A STYLIST DOSTOEVSKY HAD MANY SHORTCOMINGS. TOLSTOY ... (Barthelme, 1965, p. 143)

THE REVOLUTION OF THE PAST GENERATION IN THE RELIGIOUS SCIENCES HAS SCARCELY PENETRATED POPULAR CONSCIOUSNESS AND HAS YET TO SIGNIFICANTLY INFLUENCE PUBLIC ATTITUDES THAT REST UPON TOTALLY OUTMODED CONCEPTIONS (Barthelme, 1965, p. 54).

THE SECOND GENERATION OF ENGLISH ROMANTICS INHERITED THE PROBLEMS OF THE FIRST, BUT COMPLICATED BY THE EVILS OF INDUSTRIALISM AND POLITICAL REPRESSION. ULTIMATELY THEY FOUND AN ANSWER NOT IN SOCIETY BUT IN VARIOUS FORMS OF INDEPENDENCE FROM SOCIETY:

\section{HEROISM \\ ART}

SPIRITUAL TRANSCENDENCE (Barthelme, 1965, p. 24)

And these divergent or irrelevant fragments hinder the course of reading. But each of them in the least highlights one topic, conceiving an idea; whereas the following are, as it were, merely a mosaic, or a pile of words, conveying no meaning at all.

THE HORSEWIFE IN HISTORY

FAMOUS HORSEWIFE

THE HORSEWIFE: A SPIRITUAL PORTRAIT

THE HORSEWIFE: A CRITICAL STUDY

FIRST MOP, 4000 BC ...

THE PLASTIC BAG

THE GARLIC PRESS (Barthelme, 1965, p. 61)

SNOW WHITE THINKS: WHY AM I ...

GLASS ... HUNCHED AGAINST THE

WALL ... INTELLIGENCE ... TO

RETURN ... WALL ... INTELLI-

GENCE ... ON THE ... TO RE-

TURN ... HE'S COLD ... MIR-

ROR ... (Barthelme, 1965, p. 166)

The oddity of language itself has been self-evident. These capitalized, either complete or fragmented, clauses are sandwiched between units of consecutive pages. They neither bring the foregoing content to a conclusion, nor do they transit to the following paragraph. Say, they are contextually irrelevant.

Secondly, the readers' expectation of language itself is deconstructed. Obviously, discourse like above-mentioned would completely irrigate readers' traditional cognition of literature and language. Meanwhile, the questionnaire between part I and part II is supposed to satirize our accustomed mode of thinking and/or critical vehicles to interpret novels. The wording of it is also a parody of average questionnaire.

In most parts of the novel, self-reference or self-discussion is applied to unsettle readers' expectation. The following is a self-discussion by Snow White. Unlike figures in the Grimms' tale, each character here is self-conscious.

SNOW WHITE let down her hair black as ebony from the window. It was... out of the window. "I could fly

a kite with this hair it is so long. The wind would carry the kite up into the blue ... together with my hair black as ebony, floating there. That seems desirable. This motif, the long hair streaming from the high window, is a very ancient one I believe, found in many cultures, in various forms ... and the refreshment of my venereal life." (Barthelme, 1965, p. 80)

And self-reference occurs in natural formal languages when a sentence, idea or formula refers to itself. "This is a sentence" is a good example of self-reference. " ... For not being able to at least be civilized enough to supply the correct ending to the story" (Barthelme, 1965, p. 132) reminds the reader that the novel has no fairy end as expected.

Meanwhile, it allows readers to be reconstructive and to build his own concept on the text.

The last point concerning deconstructionism is reshaping of each fairy figure. All figures in the novel are neither absolutely good nor completely evil like their prototypes as presented in the first paper.

This paper is brought to an end by saying: on the surface, the novel deconstructs a fairy tale, namely, the values and 
moral codes it treasures: what is good, beauty and truth in comparison to what is evil, ugliness and falsity. In actuality, all transcendental convictions are perturbed, showing the helplessness and nothingness of modern life. What is more, its ultimate aim is to convince the reader that language as the carrier of meaning has lost its function as a means of communication. And it confirms that postmodernist works are deconstructive in nature as well.

\section{Cognitive ExPlanAtion}

The third paper, Ma Ying's Meaning Floating out of Fracture and Fragments: A Cognitive Approach to Understand Donald Barthelme's Snow White creatively employs theories of cognitive poetics and narratology to make catching the novel's meaning possible.

The first aspect Ma Ying highlights concerns cognitive psychology. As the theoretical foundation, the figure-ground forming mechanism is derived from Gestalt psychology. It can be put this way:

The figure is a moving or conceptually movable entity whose path, site, or orientation is conceived as a variable, the particular value of which is the relevant issue (Talmy, 2000, p. 312).

The ground is a reference entity, one that has a stationary setting relative to a reference frame, with respect to which the figure's path, site, or orientation is characterized (Talmy, 2000, p. 312).

Figure-ground forming mechanism can be interpreted like this: when we see a blackboard in the front of a classroom, we may not pay much attention to it. But a word or sentence written with a chalk on that board would draw our immediate attention. In Gestalt psychology, the word or sentence is called figure, the board ground. The ground highlights the figure which is more likely to elicit attention.

This theory explains why the reader who knows its counterpart fairy tale would automatically take its plot as the background of the novel. Thereby the content of the novel might be emphasized. As the novel consists of 107 fragments - as short as a clause, as long as 6 pages - the gaps between them are contingent upon the original plot to bridge. Say, in the course of reading, the reader would frequently take some elements of the fairy tale as referential objects to make comparisons and contrasts: some of which are in line with readers' expectations, for example, "The hair is black as ebony, the skin white as snow" (Barthelme, 1965, p. 3); the others, however, are against expectations: "She is a tall dark beauty containing a great many beauty spots, one above the breast, one above... as you go up and down:" (Barthelme, 1965, p. 3).

At the same time, words and phrases of the fairy tale in bold as well as upper case lead the reader to reshape the story, for instance:

\section{WHAT SNOW WHITE REMEMBERS: \\ THE HUNTSMAN \\ THE FOREST \\ THE STEAMING KNIFE (Barthelme, 1965, p. 39)}

In addition to Jane's jealousy, Paul's royal blood and aristocratic temperament and such, the fairy tale's equivalent characters stepping on stage one after another, unfailingly reminds the reader of the older story; and their successive appearance in the novel runs a thread through the plot to its climax-Paul is unintentionally poisoned by Jane's vodka Gibson, which is originally intended by Jane to poison Snow White - and to its end, where the Grimms' mission as the background is thus far accomplished.

The questionnaire at the end of the first chapter, which is regarded as part of intertextual strategy in the previous analysis, is, here, too, supposed to be figure-ground image, with fairy tale as ground and the novel as figure to overemphasize the content of the novel. Besides, Snow White hanging her hair out of the window is originated from the Grimms' another fairy figure, Rapunzel, who was prisoned in a high tower by a witch. With Rapunzel's plot in the setting, reactions to the hair are overexposed: Reaction to the Hair, Lack of Reaction to the Hair and Additional Reaction to the Hair open a window to the reality, satirizing loss of humanity and helplessness of survival in the modern world.

As to Snow White's response to prince's rescue, there are dual fairy settings. The one is Snow White, who is passively awaiting redemption; comparably, the other, Rapunzel, is actively searching for salvation; whereas in Barthelme's novel Snow White attempts to redeem herself, because "There is something wrong with all those people standing there, gaping and gawking. And with all those who did not come and at least try to climb to fill the role, and with the very world itself, for not being able to supply a prince" (Barthelme, 1965, p. 132). She gives up fantasy of prince and revirginizes and rises into the sky. In this way, with two fairy tales in the background, the image of characters is highlighted, bringing fractured discourse into recognizable plot.

The second point, the angle from which the reader of cognitive narratology interprets the novel, is the alternate narrating pattern: narrators switch between the first person (I, we) and the third (she, he) from time to time, with omniscient perspective and/or limited one. By perspective-alternating narrating, especially interior monologue and discourse, bizarre conflicting consciousness is revealed. "Our consciousness is the main part of the consciousness." As whether "we" can represent all of "us" is questionable, "our" narration is not necessarily reliable, so to say.

In spite of the preceding unreliability, by integrating two or more scenes of the novel together, its historical setting will be crystallized: WWII, the Korean War, poverty, shortage of food, drought, extinction of animals, stock exchange, foreign currency exchange, arms race and cold war. As a country in the Eastern Bloc during the Cold War era, China is 
mentioned several times. That is because Barthelme had been drafted into the U.S. Army and arrived in Korea on the day of the signing of the Korea Armistice Agreement and worked briefly as the editor of an army newspaper. "War on poetry" projects "war on poverty" initiated by the then President John F. Kennedy. Poverty is the major social problem of the textual realm. Because "I don't mean that the deprived people are deprived, although they are, clearly, but that even the fat are deprived" (Barthelme, 1965, p. 40). Environmental problem emerged along the course of industrialization; "Where have the buffalo gone? You can go for miles and miles and miles and miles and miles and miles and hundreds of miles without seeing a single one! And that didn't prevent them from letting the railroads grab all the best land" (Barthelme, 1965, p. 131). Food shortage, economic problems and arid weather are among factors that bring postmodern American pageant into being. The Cold War and arms race could be the horrible political background of that landscape.

The conclusion Ma Ying comes to is that cognitive poetical and narratological interpretation on Barthelme's novel provides rational and in-depth insight into the way his contemporaries lived. The apparently absurd and deliberately elegant depiction is a reflection on their anxiety over reality: industrial civilization and progress in sciences and technology unsettled utopian fantasy and challenged conventional values and moral codes. And all these arouse contemplation.

\section{CONCLUSION}

The preceding three analyses were issued around 2000 - half a century after the novel's publication (1965) in the USA, nearly two centuries after the publication of its old version, the fairy tale (1813) in Germany. Though the text on which the analyses based is its Chinese version; the analyses themselves are written in Chinese; both facts do not prevent their varied interpretations on the text: Intertextual reading focuses on similarities and dissimilarities between the tale and the novel; deconstructive interpretation topples conventional thinking mode of literature as well as its carrier-language; whereas the narratological explanation enables the reader to see the history through the bizarre collage. With multiple literary theories, the reader could set a comprehensive view of the text; and the more angles from which it is viewed, the more insights are provided into the masterpiece, which is open to interpretation.

As for the relationship between the old tale and the new novel, the intertextual reading regards the former as a benchmark; the deconstructionist takes it as the object of deconstruction; whereas the cognitive narratologist visualizes the old story, setting the novel in the forefront with the tale in the background. Whatever the role the ancient tale plays in different analyses, it is an indispensable part, as it were, for interpretation on this postmodern novel. Namely, multiple layers of meaning between the lines of the novel will not be deciphered without reference to or acquaintance with the old fairy tale. This partly explains one of the reasons why the postmodernist novel is hard to understand.

\section{ACKNOWLEDGEMENTS}

This thesis becomes a reality with the kind support and help of many individuals. Foremost I would like to express my sincere gratitude to my advisor Prof. Haixia Yang for the continuous support of my research. A special thank goes to Prof. Liang Meng, who checked my thesis, word by word, sentence by sentence to figure out grammatical errors and incorrect usages which I was eager but failed to recognize. I would also like to acknowledge with much appreciation Prof. Yuehui Niu, who offered me valuable advices in modifying this thesis. I am highly indebted to NCEPU College of Foreign Languages for providing necessary information regarding this research and for their support in completing this endeavour.

\section{REFERENCES}

[1] Barthelme, D. (1965). Snow White. Toronto: McClelland; Fairfield: Graphics.

[2] Barthes, R. (1975). The Pleasure of the Text (Richard Miller, Trans.). New York: Hill and Wang.

[3] Bertens, H. \& Fokkema, D. (1997). International Postmodernism: Theory and Practice. Amsterdam and Philidelphia: John Benjamins.

[4] Genette, G. (1997). Palimpsests: Literature in the Second Degree (Channa Newman \& Claude Doubinsky, Trans.). Lincoln NE and London: U of Nebraska P.

[5] Hassan, I. (1987). The Postmodern Turn: Essays in Postmodern Theory and Culture. Columbus: Ohio State U P.

[6] Kristeva, J. (1986). The Kristeva Reader. Toril Moi (Ed.), Word, Dialogue and Novel. Oxford: Basil Blackwell.

[7] Li Yuping. (2004). Foreign Literature Studies. Intertextual Interpretation on Donald Barthelme's Snow White, 6, 67-71.

[8] Ma Hanguang. (2003). Snow White and the Postmodern Deconstruction, Journal of Qiqihar University. 30, 1-4.

[9] Ma Ying (2015). Meaning Floating out of Fracture and Fragments: A Cognitive Approach to Understand Donald Barthelme's Snow White, Academics. 202, 131-38.

[10] Talmy, L. (2000). Toward a Cognitive Semantics. 1 Vols. Cambridge: MIT P.

Haixia Yang, born in Henan province, China, an Associate Professor with the School of Foreign Languages, North China Electric Power University, Beijing, China. Research interests cover Linguistics and Foreign Language Teaching. 
Liqing Kang A graduate student for his master's degree at the School of Foreign Languages, North China Electric Power University, Beijing, China, focusing mainly on Anglo-American literature. 